\title{
An Assessment Tool of Competencies for Inclusive Teachers of Regular Schools
}

\author{
Priti Jadhav* and Nisha Valvi \\ Department of Education and Extension, Savitribai Phule Pune University, Pune, India \\ *Corresponding author: jadhavpriti087@gmail.com
}

\begin{abstract}
Students with diverse abilities are increasingly present in primary and secondary schools. The inflow of special need students in the mainstream schools is become a challenge for in-service as well as new coming teachers. A teacher must know how to deal and cope up with different learning needs. The importance of the tool was to explore the competencies (knowledge, skill, attitude) of inclusive teachers who are working with students with diverse abilities in regular classroom. The purpose of this research was to develop a tool to assess teachers' competencies with respect to knowledge, skill, attitude. A total of 50 teachers from 5 schools participated. Result showed that developed tool was effective to check competencies required for inclusive teacher.
\end{abstract}

Keywords: Assessment, tool, inclusive teacher, competencies, diverse abilities

Inclusive education means to include students who have the ability to learn irrespective of physical, intellectual, emotional, social, linguistic conditions. It includes all those who are have the capability to learn but learn differently. It is about breaking down the barriers not only in the physical domains but also emotional, social and intellectual domain. Inclusive education has been internationally recognized as a philosophy for attaining equity, justice of quality education for all children, especially those who have been traditionally included from mainstream education for reasons of disability, ethnicity, gender or other characteristics. While inclusive education has been implemented successfully in many countries, other countries are still in the process of achieving this goal (Dinh Thi Nguyet and Le Thu Ha, 2010).

Some countries have been successful in promoting inclusive education practices \& policies that remove barriers \& create conditions which enable all children to learn. However, in poorer developing countries the process of creating an inclusive system is more difficult factors such as lack of available funding, administrative \& policy level support, \& trained personnel pose challenges that can slow down progress (Dinh Thi Nguyet and Le Thu Ha, 2010).

The main objective of the research was to identify competencies of inclusive teachers to develop their performance in teaching inclusive classroom. Once they know which competencies are lacking into them, they will improve accordingly. The inflow of the SEN children in the mainstream schools has been a challenge for the new and the old teachers to deal and cope up with different learning needs. It will be helpful for them to deal with SEN children and regular children at a time in inclusive classroom.

To establish the balance between the students of mainstream education and SEN children, various policies are put on papers but the implementation is lacking. Apart from the change in the curriculum in school to deal with SEN children, measure need

\footnotetext{
How to cite this article: Jadhav, P. and Valvi, N. (2020). An Assessment Tool of Competencies for Inclusive Teachers of Regular Schools. Educational Quest: An Int. J. Edu. Appl. Soc. Sci., 11(2): 83-85.

Source of Support: None; Conflict of Interest: None (a) 9
} 
to be taken to ensure that not only the curriculum for SEN children in mainstream school is revised but also the Curriculum for the pre service teacher training programs.

Training teachers in teaching methods that include students of all ability levels, as well as spreading awareness to teachers about the importance and benefits of inclusion, is one of the most important parts of implementing a system of inclusive education, because the teachers are the people on-the-ground who are going to accommodate the students.

A teacher must have knowledge of his subject, methods \& techniques of teaching which affect his teaching. Committee on plan projects of the planning commission, stated in their draft report- "Modern education aims at education of the whole person. So, every teacher should have a deep knowledge \& understanding of children \& a skill for applying that knowledge \& understanding" For efficiency \& effectiveness training is necessary. If a person is trained before being employed in a job this is called pre-training. By having some pre-training, he will get success \& full satisfaction in his job.

The attitude of the teachers is equally important as they are the main source of Knowledge. If they are prejudiced against either the disabled or nondisabled or one group or the other, there are going to be more problems. Teachers will need to reorient to the concept and practice of inclusion. Appropriate training programmes for the teachers will bring about an attitudinal change. Teaching in an inclusive school demands greater conceptual, technical and human skills; hence it is an urgent need for a course inclusive education in teacher training programmes in colleges of education and university departments of education.

According to Sorenson, "An attitude is a particular feeling about something. It therefore involves a tendency to behave in a certain way of situations which involve that something, whether person, idea, or object. It is partially rational, partially emotional and is acquired, not inherent in an individual." It states that an individual behaves in a certain way when he is needed to respond to a particular object for which he has developed a positive or negative attitude. In all the cases, attitude is acquired and learned through varying experiences.
Skills are specific behaviors or activities which an individual requires to do a particular job or task. It refers to a tube doing part of the human. The manner in which he has to do the work is a skill. As the skill of questioning, skill of illustrating, demonstrating etc. Therefore, the present study was to aimed to develop a tool based on three major factors i.e. knowledge, attitude, skill which will help teachers to handle inclusive classroom.

\section{METHOD}

Participants - This study was conducted with a sample of 50 teachers from 5 schools in Pune. All teachers were employed at Primary school. Regarding level of education all had completed their graduation. The schools comprised of special schools. All schools have classrooms for special education.

Procedure - The school administrative authorities were contacted and given an explanation of the study purpose. They were requested for permission to distribute the questionnaires. The schools head teacher responsible for distributing, returning the questionnaires with the guideline provided by the investigator.

Measures - To develop a tool a rating scale is developed, which was 5-point scale based on Likert scale. Total 30 statements were added in the scale out of which 9 are negative and 19 are positive statements. These statements are based on sub dimensions, skill and attitude as follows,

\section{Knowledge:}

1. Types and characteristics of knowledge

2. Mainstreaming

3. Constitutional and policies, schemes related to DC

4. Inclusive education

5. Methodology.

Skill:

1. Adjustment with academic environment and general environment

2. Socio-psycho physical adjustment

3. Professional relationship adjustment

4. Job satisfaction. 


\section{Attitude:}

\section{Mental ability}

2. Adaptability

3. Attitude towards DC

4. Professional interest.

This rating scale is given to the 30 in service teachers for evaluation. This tool was not standardized.

Data Analysis - For data analysis response options ranged from 1 (Always) to 5 (Never). Items were developed to examine the knowledge, attitude and skill of inclusive teachers towards inclusion of students with diverse needs in schools.

Results - Rating scale was evaluated on regular school teachers to check their competencies. It also assesses which competencies are lacking or already present into them to become a successful inclusive teacher. Successful implementation of Inclusive education is possible if the teachers have sufficient knowledge, attitude and skills towards inclusive education. The best way to assess these all by using developed tool i.e. rating scale. It is a self-explanatory tool which tells teachers about their competencies.

\section{REFERENCES}

Balasundaram Pramila. 2005. The Journey towards Inclusive Education in India, Presented at Seisa University, Japan. (page 5)

Chadha, Anupriya, A Journey from Isolation to Inclusion, Perspective in special Needs Education in India, Govt. of India, New Delhi.

Dinh Thi Nguyet and Le Thu Ha. 2010. Preparing teachers for inclusive education.

McDonnell, Lorraine M., Ed. \& et al. 1997. Educating One E All: Students with Disabilities and Standards-Based Reform.

Hooda Madhuri, Nagpal Chirag, 2011. Special Education, Agra, Agarwal Publications.

http://www.crsprogramquality.org/storage/pubs/education/ edhowto_vietnam2.pdf

ICE Conclusions and Recommendations, UNESCO-IBE 2008.

Isave Madhuri. 2011. Efficacy of integrated model base on biological science inquiry training model and stress reduction model to develop inquiry approach and reduce stress visually impaired students.

John W. Best and James V. Kahn. 2005. "Research in Education" seventh Edition, (P-20, 132, 107)

Keith Topping and Sheelag Maloney. 2005. The Rutledge Flamer Reader in Inclusive Education, New York: Rutledge Flamer.
KESSLER, Naomi. 2010. Children's attitudes and group norms towards classmates of lower and higher ability.

Len Barton, 2003. Inclusive Education and teacher education, London: IOE, University of London.

Lindsay, Katharine Gifford, 2007. Inclusive education in India: Interpretation, Implementation and Issues, United Kingdom: CREATE 2007 (page 20)

McMANUS, Tara. 2007. Tribes: A Program of Evaluation of Effectiveness of Promoting Inclusive Attitudes and Practices.

Md. Saiful Malak, Pre-Service Teachers' Responses to Include Students with Special Educational Needs in Regular Classrooms University of Dhaka, Bangladesh, Inclusive Education Reform in Bangladesh:

Mohammed Al Zyoudi, Abdel Aziz Al Sartwai and Hamzeh Dodin. Attitudes of Pre-service Teachers towards Inclusive Education in UAE and Jordan (a comparative study).

Muhammed Mahbubur Rahaman, Department of Special Education, Institute of Education and Research, University of Dhaka, Bangladesh. Attitudes and Concerns of Teacher Educators towards Inclusive Education for Children with Disabilities in Bangladesh.

Paul A. Bartolo. 2010. The Process of Teacher Education for Inclusion: The Maltese experience.

Perception about education of disabled children, Journal of Indian Education Vol. xxx, No. 1 (2004, May), NCERT, pp. 22-23.

Mangal, S.K. 2008. Essentials of Educational Psychology, Delhi, Adarsh Gosh (page 329).

Singh, Y.K. 2010. Micro Teaching. Delhi, APH Publishing Corporation (page 28).

Subban and Sharma, 2006. Concerns and attitudes towards inclusive education.

Thankur, A.S. and Thakur, Abhinav Thakur. 2012. Inclusive Education, Agra: Agarwal Publications.

Thankur, A.S. and Thakur, Abhinav Thakur. 2012. Inclusive Education, Agra: Agarwal Publications, pp. 6-7.

Annemarie Carroll, Chris Forlin, and Anne Jobling. 2003. The Impact of Teacher Training in Special Education on the Attitudes of Australian Preservice General Educators towards People with Disabilities.

UNICEF, 2003. Examples of Inclusive Education India: Nepal. (Page 8).

Bintade, V.R. "Methods of Educational Research" Pune, Nutan Prakashan, pp. 87.

Van Reusen, Anthony K: Shoho, Alan Barker. 2002. High School Teacher Attitude toward Inclusion.

Williams, Amanda. 2005. Assessing Prospective Teachers' Attitudes Toward Students with Behavior Difficulties over the Course of Pre-service Training. 
